\title{
An Exploration on the Practice Space and Implementation Paths of \\ Green Supply Chain in Deepening Reform and Opening Up in Hainan
}

\author{
SONG Ke-wei1, a, ZHOU Mi², b \\ 1School of Humanities and Social Sciences, Beihang University, Beijing 100191, China; \\ ${ }^{2}$ Chinese Academy of International Trade and Economic Cooperation, Ministry of Commerce, PRC, \\ Beijing 100710, China.
}

askw007@126.com, bdatamaster@163.com

Keywords: green supply chain, practice space, implementation paths, Hainan.

\begin{abstract}
This paper briefly reviewed the basic concept, research and practice basis of green supply chain, analyzed the requirements of green development for deepening Hainan's reform in terms of strategic positioning, basic principles, and development goals. The essential foundations and advantages for Hainan to promote the development of green supply chain were then discussed. In addition, the space for practicing green supply chain in Hainan was analyzed from both macro and micro perspectives with short-term and long-term development paths of green supply chain proposed. Finally, four possible risks and precautions were explored.
\end{abstract}

\section{Introduction}

Green development is one of the major guiding principles for the future development of China's economy and society. To achieve green development, it is necessary to effectively handle the whole-chain coordination throughout product life cycle so that relevant stakeholders, such as the government, enterprises, intermediary organizations and consumers and so on, can actively get involved. Green supply chain is an important tool to realize this goal. Forty years after China's reform and opening up, Hainan has once again become an experimental field and leader in comprehensively deepening reform. Not only does it have a significant practical value, the exploration on green supply chain practice in Hainan also provides a reference for the sustainable development of China and other economies.

\section{Basic Concept, Research and Practice Basis of Green Supply Chain}

The beginning stage. Green supply chain management originated in the United States in the 1970s with the addition of environmental factors in the study of logistics management as the main research foundation. Commoner [1] believed that "technical theory" and "profit theory" are the main reasons resulting in environmental problems. From the 1970s to the 1990s, the United States was most concerned about environmental issues, during which the concept of supply chain was proposed and developed. The environmental protection movement and the trend of resource integration and development provided the basis for the creation of green supply chain.

The forming stage. Research on green supply chain became prominent mainly in the 1990s. Led by the green procurement proposed by Webb in 1994 [2], the manufacturing research association of Michigan State University, funded by the National Science Foundation, conducted the 
"Environmentally Responsible Manufacturing" study. The project team proposed the concept of green supply chain in 1996 [3]. In 1997, Min et al. put forward the importance of reducing waste generation in procurement in a study of green supplier selection [4]. In 1998, "Environmentally Conscious Supply Chain Management" was published in the United States, which is primarily an introduction to analysis tools and cases. In 1999, Beamon [5] \& Hock [6] introduced environmental factor into supply chain, proposing ecological balance maintenance in actual operations. In addition, green supply chain management plays an important supporting role in enhancing corporate performance [7], saving money and resources and establishing corporate brand, able to reduce the consumption of social resources and the impact on the environment in the production process.

The developing stage. In the 21st century, the research of scholars at home and abroad on green supply chain in both depth and breadth has attracted more attention. Zsidisin [8] believed that the main content of green supply chain management includes planning, design, procurement, production, distribution, use and reuse, as well as the management decisions, actions, and cooperative relationships regarding an enterprise's internal supply chain on an environment-friendly basis. At the international level, the journal Greener Management International launched a special issue-Greening Supply Chain Management, in 2002, providing a platform for research on green supply chain. Based on the full life cycle, Giannis et al. considered the environmental impact of the battery manufacturing industry and analyzed the reverse logistics of used batteries [9]. Sonesson et al. studied the influence factors of supply chain to the environment considering various milk production links by the means of the life cycle method with an analysis system established for food production process and transportation [10].

\section{Requirements of Green Development in Comprehensively Deepening Reform in Hainan}

At the 40th anniversary of China's reform and opening up, comprehensively deepening reform and opening up is not only a critical way for Hainan to break through its own development constraints, but also an important precursor in accumulating reproducible and propagable experiences and leading the practices of reform and opening up in China. The "Guidance on Supporting Hainan's Comprehensive Deepening of Reform and Opening-up”, issued on April 11, 2018, put forward clear requirements on green development.

In terms of strategic positioning. Hainan should be constructed as a national pilot zone for comprehensively deepening reform and opening up and ecological conservation, an international tourism center, and a national supply zone for major strategic services, contributing to the construction of a prosperous, democratic, civilized, harmonious, beautiful and modernized socialist country. As a key part of the new development concept, green development is not only a direction for China's future development, but also an indispensable path for Hainan to promote its opening up. The development concept of "Lucid waters and lush mountains are as valuable as gold and silver" has been implemented in all tasks, making it a key feature and nameplate for Hainan's comprehensive deepening of reform and opening up.

From the basic principles. Hainan should adhere to overall promotion and steady implementation, while strengthening systemic and coordinated reform. Green supply chain as a reference index will help reduce the cost of development and improve the effectiveness and sustainability of its development. Hainan persists in integrated land and marine conservation and development, so as to form a new pattern of coordinated development of land and sea resources, industries and spaces. To avoid over exploitation and utilization of single resource, it is required guiding under the concept of sustainable development. 
In terms of development objectives. Hainan should take the lead in realizing modernization in the middle of this century, building a new and beautiful Hainan with economic prosperity, social civilization, ecological livability and comfortable life. The goals require effective use of social resources, reduction of the impact of economic development and socio-economic activities on the environment, and reliance on the path of green development.

\section{The Feasibility of Supporting Hainan's Comprehensive Deepening of Reform with Green Supply Chain}

Green supply chain is concerned about environmental impact throughout product life cycle from design to recycling, focusing on prevention rather than end-of-pipe solutions. In 2014, the topic of green supply chain at the APEC Beijing Summit became a consensus and important achievement of all parties. APEC green supply chain cooperation network was established with the first demonstration center set up in Tianjin, an important practice of all parties to promote green development.

Tianjin's green supply chain practice has been fruitful, playing an active role in saving resources, exploring standards and norms, and reducing the environmental impact of economic development, which provides experience in further promoting green supply chain. Green supply chain can be accelerated by reviewing production process from the perspective of the entire life cycle, as well as forcing carbon emission reduction of the entire supply chain through the power of the market, international trade and green procurement.

APEC is a leader in many international practices, including cutting environmental product tariffs in international trade, among others. From APEC's autonomous actions to the WTO's compulsory concessions, APEC's green initiative has played a more significant role. Using the experience and ideas of APEC for reference, the WTO launched the Environmental Goods Agreement (EGA) in July 2014 to push all participants to cut environmental product tariffs to zero. 14 WTO members including China, the United States and the European Union participated in the negotiations. Although the negotiating stopped due to the gap in interest claims of various parties, the definitions of low-carbon and low-energy-consuming commodities and the transitional measure of phased bidding are beneficial to creating a green development environment.

Hainan has essential foundations and advantages for promoting the development of green supply chain, which are mainly manifested in the following four aspects:

First, excellent ecological resources. Diversified marine and land ecosystems with abundant resources offer a strong advantage in ecological and environmental resources. By the end of 2017, the province's forest coverage rate reached $62.1 \%$, and the urban green area rate in cities and counties was over $35 \%$. The road greening compliance rate exceeded $95 \%$, the ambient air quality reached $98.7 \%$, and the water quality of urban (town) water sources $100 \%$ met the required standards.

Second, suitable industrial conditions. Hainan's industries are highly characterized, possessing a good industrial foundation and a large development space. According to statistics, in 2017, the proportion of the three industries in Hainan Province was 22:22:56, while China's overall proportion was 8:40:52. It can be seen that agriculture and service industry have a higher proportion in Hainan's economy, and the secondary industry with relatively greater environmental impact takes up a relatively low portion. Moreover, the output of heavy industries decreased by $2.3 \%$ while that of light industries increased by $7.9 \%$ in 2017. The impact of industrial activities on Hainan's economy and society is more controllable, and so it is more viable to use the green supply chain approach to reduce negative environmental impacts in addition to lower transformation costs. 
Third, clear legal constraints set by the government. The Hainan government has a strong sense of responsibility for economic development under environmental protection. It sets up necessary legal protection for green development and regulates corporate behaviors through statutory provisions. The "Hainan Environmental Protection Regulations" was issued as early as 1990 when the province was established. In 2011, the Haikou Intermediate People's Court set up an environmental protection trial court, and the "Hainan Provincial Ecological Protection Red Line Management Regulations" was issued and implemented in 2016 in the form of legislation of the National People's Congress. The "Hainan Environmental Protection Regulations" specifically requires changing the mode of economic development, encouraging and supporting clean production and resource recycling, and promoting advanced environmental protection technology, along with vigorous development of recycling and low-carbon economy, advocacy of green consumption, and formation of green development approaches and lifestyles.

Fourth, the construction of pilot free trade zone and free trade port providing greater space for exploration. Establish a high-standard, high-quality pilot free trade zone throughout the territory. With institutional innovation as the core, it implements highly liberal and convenient trade and investment policies, strengthens reform system integration, and attracts global capital to enter the market. Hainan explores the construction of a free trade port with Chinese characteristics. Instead of focusing on entrepot trade, processing and manufacturing, it emphasizes the leading positions of modern service industries and high-tech industries, creating conditions for further expansion of visa-free entry. Not only serving as a concept innovation for exploration and promotion in the practice of furthering Hainan's opening up, green supply chain also has realistic demand support. In the practice of substantial market opening, the driving force for global capital concentration in Hainan has enhanced and the demand of the accelerated population flow has become more diverse. As a result, there has been a growing reliance on economic and social development approaches that satisfy high quality demands while reducing negative environmental impact, which creates better conditions for the implementation of green supply chain.

\section{Practice Space and Path Design of Hainan's Green Supply Chain Development}

Practice Space. Green supply chain is in fact an important tool for linking macro- and micro-scale economic activities. On the macro level, the promotion of green supply chain can help reduce the negative impact of economic activities on the environment and achieve the goal of green development. On the micro level, green supply chain requires all related parties to examine their actions in the product life cycle from a more holistic perspective, constrain environmentally unfriendly behaviors, and promote the application of innovative practices, while addressing, to certain extent, the resource and environmental constraints, the need for economic and social development, and the demand for improved and more efficient consumption. Hainan has a broad space for promoting green supply chain practices: First, there is a strong demand for the transformation of the existing economy and society. Although its environment is generally good, there are still many weak links, such as urban river water quality compliance rate only at $56.5 \%$, decentralization and low efficiency of agricultural activities to be improved, and so on. Second, it proposes to deepen opening up in key areas including seed industry, medical care, education, sports, telecommunications, the Internet, culture, maintenance, finance and shipping, which inevitably brings in various elements including goods, services, funds, technology, personnel, etc. Besides a significant increase in the carrying capacity of its economic environment, effective constraint on various new economic activities will be required as a result of the aggregation. It is easier to obtain 
the recognition of all parties by regulating various economic activities with green supply chain compliant with international conventions and rules.

Path Design. The path for promoting green supply chain in Hainan may be divided into two phases. In accordance with Hainan's goal of comprehensive opening up, the quality and benefits of economic growth shall be significantly enhanced by 2025. For the short-to-medium term of 7 years from now, green supply chain may be promoted according to the following path: (1) Establish suitable green supply chain specifications and standards. There has not yet been formed an internationally recognized standard. Drawing on the practices and experience of the APEC initiative, Tianjin, Dongguan and other places, as well as Wal-Mart and other multinational corporations, Hainan is to establish standards and specifications that suit its own needs and cover important industry sectors. (2) Deploy green supply chain in a comprehensive manner in the planning stage. Hainan insists on drawing the blueprint from the start to the end. The existing planning will have a major impact on its future development. In the initial stage of the construction of the free trade zone and free trade port, the concept of green supply chain should be fully implemented, so as to set the tone and lay the foundation for the subsequent development. (3) Introduce advanced institutional and enterprise practices in green supply chain. Institutions and companies with rich green supply chain experiences and greater influence will be encouraged and supported to develop in Hainan, which will be set as benchmarks and models. (4) Creating a commercial atmosphere with development led by green supply chain. Through industrial clusters and collaboration, the upstream and downstream companies in the industrial chain are guided to follow green supply chain standards and advocate the concept of green social development. The practicality will be enhanced to gradually form a business atmosphere supported by green supply chain.

In the long run, the development of green supply chain in Hainan should meet the goal of leading modernization in China by the middle of this century. The path is as below: (1) Strengthen its influence in green development. Its development experiences and standards should gain boarder recognition, serving as an important criterion for the sustainable development of China's economy and a critical reference standard for international development mechanisms such as APEC and the Belt and Road Initiative. (2) Accumulate all types of resources compliant with the development needs of green supply chain. Establish a huge attraction to draw enterprises, R\&D institutions, scientific and technical personnel, financial institutions, and management personnel related to global environmental protection and green supply chain, in order to form a scale advantage. (3) Set a mechanism for the optimization of green supply chain cycle. Under the background of technological progress and social development, self examination and evolution of green supply chain should be enhanced to ensure that it will be able to self-optimize and continuously improve.

\section{Main Risks and Precautions of Developing Green Supply Chain in Hainan}

Risk of spillover as a result of changes in the global economic and trade environment. The global economy has apparently revived since 2017. However, the United States frequently provokes trade disputes for its domestic interests, seriously interfering with market expectations and causing a significant impact on trade and investment activities. Withdrawal from the Paris climate agreement, increased efforts in the development of traditional energy sources, and reduced efforts in environmental protection, etc., aroused changes in the attitude of many stakeholders towards the development of low-carbon and environment-friendly economies, which may influence China's green supply chain development through international economic and trade activities and technical cooperation. That has a negative impact on the promotion of green supply chain. In response to the 
impact, it is necessary to continue to promote green supply chain through phased actions of definitive laws and regulations, planning and implementation plans, while seeking the support of more countries and international organizations to form a macro environment benefiting the development of green supply chain.

Risks in economic development and model transformation. Although Hainan will meet less difficulty in the transition from economic development to green development, there are still considerable risks. Successful transformation requires the recognition and promotion of market consumers. Forming an attractive mechanism may require abandoning the existing development model. There may be bottlenecks in terms of supply and demand matching in the labor market, and the coordination of the assessment and support mechanisms of industrial chains. Even worse, economic deceleration may occur in a short term. To adapt to the changes, leading enterprises should be used as pilots to gradually advance the transformation and accumulate experience. For industries that cannot complete the transformation and are inconsistent with the direction of economic development, they should be encouraged to transfer or upgrade with compensation mechanisms effectively exerted.

Risk of monopoly by pioneers that eliminates competition. In some cases, green supply chainrelated procurement and trade become green barriers in achieving other goals. In extreme cases, they may even become the means by which industry leaders crowd out competitors and monopolize the market. Without the balance between green development and rational and orderly market competition, not only will the economic and social development goals fail, but a market monopoly may take shape under the condition of insufficient competition, thus resulting in loss of the driving force for innovation, and harming consumer welfare, which are detrimental to healthy development support for green supply. To ensure the role of the competition mechanism, international standards should be followed during the establishment of relevant green supply chain standards and mechanisms, opinions and suggestions from all parties should be fully heard, and protection of SMEs should boosted to favor them in terms of certification support, capacity building and financial support.

Risk of sharing increased costs due to the promotion of green supply chain. As a pioneer in green supply chain, it will inevitably have to pay additional costs, including both the additional costs of operating activities in accordance with relevant concepts, and the costs of trial and error. In case all the costs are borne by the pioneers, it may significantly reduce the enthusiasm of various parties in promoting green supply chain. In fact, implementing green supply chain will be beneficial to the economic and social environment, the providers of goods or services, and consumers. To match the responsibilities with rights, appropriate division of responsibilities and powers may be done according to the economic development characteristics of public service and private sectors. In the short term, the government may shoulder more responsibilities in basic environmental construction, purchase of public services, etc., while gradually withdrawing with the popularization of related practices in green supply chain so that companies practicing green supply chain in Hainan are able to cultivate their brands, improve technology and gain experience in addition to higher economic benefits, laying the foundation for extending and promoting it to their global networks.

\section{References}

[1] Commoner B. The closing circle: Nature, man, and technology[M]. New York: Knopf, 1971.

[2] Webb L. Green purchasing: Forging a new link in the supply chain[J]. Resource, 1994, 1(6): 1418. 
[3] Handfield R B. Green supply chain: best practices from the furniture industry[C]. Proceedings, Annual Meeting of the Decision Science Institute USA, 1996(3):1295-1297.

[4] Min H, Galle W P. Green purchasing strategies: Trends and implications [J]. Journal of Supply Chain Management, 1997(3):10-17.

[5] Beamon B M. Designing the green supply chain [J]. Logistics Information Management, 1999(4): 332-342.

[6] Hoek R I V. From reversed logistics to green supply chains [J].Supply Chain Management, 1999(3): 129-135.

[7] Corbett C J, Klassen R D. Extending the horizons: Environmental excellence as key to improving operations [J]. Manufacturing \&Service Operations Management, 2006, 8(1): 5-22.

[8] Zsidisin G A, Siferd S P. Environmental purchasing: A framework for theory development [J]. European Journal of Purchasing \&Supply Management, 2001(1): 61-73.

[9] Tsoulfas G T, Pappis C P, Minner S. An environmental analysis of the reverse supply chain of SLI batteries [J]. Resources Conservation \& Recycling, 2002, 36(2): 135-154.

[10] Sonesson U, Berlin J. Environmental impact of future milk supply chains in Sweden: A scenario study [J]. Journal of Cleaner Production, 2003, 11(3): 253-266. 